\title{
Orçamento Público como Mecanismo de Planejamento para a Gestão
}

Hellen Martins de Almeida ${ }^{1}$; Antonia Vadelucia Costa ${ }^{2}$

Resumo: O orçamento é composto por um sistema de planejamento integrado que contém leis orçamentárias de caráter preventivo e autorizativo, contendo a previsão de receitas e fixação de despesas. Para tanto, o presente estudo teve como finalidade demonstrar a importância do Orçamento Público como ferramenta de planejamento visando a execução do mesmo, trazendo bons resultados à Administração Pública. Para atingir a essa finalidade, apresenta-se uma breve evolução histórica do orçamento durante os anos, os principais conceitos, características, tipificações, princípios e leis a ele incorporados tendo como resultado a necessidade de uma melhor programação e aplicação dos recursos públicos. Também foi abordada a importância de promover o equilíbrio nas receitas e despesas, colocando em destaque o planejamento, o controle e a clareza nas atividades do Setor Público, visto que esses serviços são executados buscando satisfazer as prioridades e as demandas da coletividade. A Metodologia utilizada para o desenvolvimento do estudo é de caráter bibliográfico, uma vez que utilizou-se de obras já publicadas sobre o assunto.

Palavras Chave: Orçamento Público. Ferramenta. Administração Pública.

\section{Public Budget as a Planning Mechanism for Management}

\begin{abstract}
The budget is composed of an integrated planning system that contains budget laws of a preventive and authorizing nature containing the forecast of revenues and expenses. Therefore, the purpose of this study was to demonstrate the importance of the Public Budget as a planning tool aiming the execution of the same, bringing good results to the Public Administration. To achieve this, a brief historical evolution of the budget over the years, the main concepts, characteristics, typifications, principles and laws incorporated into it are presented, resulting in the need for a better programming and application of public resources. The importance of promoting a balance in revenues and expenditures will also be addressed, emphasizing planning, control and clarity in the activities of the Public Sector, since these services are executed in order to satisfy the priorities and demands of the community. The Methodology used for the development of the study, is of a bibliographic character, since it was used of works already published on the subject.
\end{abstract}

Keywords: Public Budget. Tool. Public administration.

\section{Intodução}

Em toda tarefa que o ser humano pense em desenvolver, em especial aquelas que exigem um nível maior de dificuldade e perfeição é preciso ter um planejamento, pois é através do

\footnotetext{
${ }^{1}$ Concludente do Curso de Ciências Contábeis do Centro Universitário Dr. Leão Sampaio - Unileão Juazeiro do Norte - Ce. E-mail: hellenmartins3530@gmail.com;

${ }^{2}$ Orientadora. Ms em Ciência da Educação pela UTIC-PY. Docente do Centro Universitário Dr. Leão Sampaio - Unileão Juazeiro do Norte-Ce. E-mail: valdeluciacosta@ hotmail.com;
} 
referidos que são evitadas falhas futuras que possam ocorrer na execução das atividades.

Segundo Angélico (2014 p.19), “O orçamento é um programa de custeios, investimentos, inversões, transparências e receitas, propostos pelo Poder Executivo para um período financeiro, e aprovado pelo Legislativo". O mesmo é de total relevância para a Administração pública, pelo fato de ser um instrumento governamental que planeja as atividades do Setor Público e organiza de forma adequada e com clareza os recursos de uma sociedade, buscando aloca-los de maneira que possa satisfazer as necessidades de toda uma coletividade.

A Constituição Federal de 1988, em seu art.165, instituiu como mecanismos de planejamento as seguintes Leis: Plano Plurianual, Lei das Diretrizes Orçamentárias e Lei Orçamentária Anual. Esses dispositivos servem de base para elaboração e execução do Orçamento Público.

Planejar no setor público é essencial, visto que a Administração Pública é responsável por desenvolver serviços buscando a satisfação da coletividade, então é preciso arquitetar tudo de forma que não aconteçam erros.

O presente estudo tem como objetivo geral demonstrar a importância do Orçamento Público como ferramenta de planejamento para a gestão, e como específicos destacar a importância do Orçamento Público como um instrumento para planejar as atividades da Gestão Pública de uma forma transparente e eficiente e comprovar a relevância do mesmo.

Justifica-se esse estudo pela necessidade de deixar claro para a sociedade como funciona o Orçamento Público e quais são os seus mecanismos de planejamento que auxiliam o gestor na busca pela eficácia, clareza e transparência dos trabalhos públicos.

A metodologia utilizada para o desenvolvimento do presente estudo, deu-se através a pesquisa bibliográfica, tendo como base a Constituição Federal de 1988 e demais obras publicadas sobre o assunto.

O Orçamento Público é um dispositivo presente na Constituição Federal Brasileira ocupando um importante papel na Gestão Pública como instrumento de Planejamento.

\section{Administração Pública}

Administrar é uma tarefa bastante complicada, principalmente se tratando da Gestão Pública. É notório que a busca por satisfazer as demandas e necessidades de uma coletividade 
induz todos os âmbitos do Poder Público irem à procura de mecanismos que possam servir de auxílio para o planejamento e desenvolvimento de suas tarefas.

\begin{abstract}
A administração pública em sentido amplo compreende: o governo (que toma as decisões políticas), a estrutura administrativa e a administração (que executa essas decisões). Em sentido estrito compreende apenas as funções administrativas de execução dos programas de governo, prestação de serviços e demais atividades (PALUDO, 2013, p. 35).
\end{abstract}

Kohama (2014) relata que a Administração Pública é toda instrumentalização do Governo que busca desempenhar serviços de boa qualidade e confiáveis para que a população sinta-se satisfeita.

No art. 37 da Constituição Federal de 1988, consta que a Administração Pública é dividida em Direta e Indireta, em todos os âmbitos do Governo: União, Estados, Distrito Federal e Municípios.

Para Bächtold (2012, p.75), a Administração Pública Direta “É aquela que possui autonomia política, financeira e administrativa. É realizada diretamente pela estrutura do governo. No âmbito Nacional é o Presidente da República auxiliado pelos Ministros de Estado.” Ou seja, a Administração Direta é composta pelos órgãos que estão diretamente ligados ao Poder Executivo e não possuem personalidade Jurídica própria.

Já a Administração Indireta, segundo Ávila (2012), é composta por entidades que são autorizadas pela a Administração Direta a desempenhar diversos papéis em setores diversos da Sociedade, e responsável por prestar serviços de qualidade à população. Esta possui personalidade jurídica própria e é composta por: Autarquias, Fundações, Empresas Públicas e Sociedade de Economia Mista.

A Gestão pública é uma importante ferramenta do Estado que conta com diversos colaboradores para ser colocada em prática; é importante salientar sua relevância para o país, pois a mesma é responsável pelo andamento dos serviços públicos que são fundamentais para suprir as necessidades da coletividade. Cabe à sociedade decidir de forma precisa quem irá eleger para integrar esse projeto tão significativo para a População.

\title{
Origem do Orçamento
}

Estudos revelam que o orçamento teve origem na Inglaterra, quando em 1215 foi outorgada a Carta Magna, pelo Rei João Sem Terra, precisamente em 15 de junho de 1215. O artigo 12 desta Carta determinava que: "Nenhum tributo ou auxílio será instituído no Reino, 
senão pelo Conselho Comum, exceto com o fim de resgatar a pessoa do Rei”. A referida carta Foi o pilar para o surgimento do Orçamento Público (MAIA, 2010).

Conforme Silva (2011), naquele século prevalecia uma espécie de Regime Parlamentar composto somente pelos barões e pelo clero, sendo excluído o restante da população; os nobres não se preocupavam com as obrigações do reino, mas sim com os impostos que eram obrigados a pagar; foi à partir daí que se iniciou a luta pelo controle dos Gastos Público.

Segundo Viana (1950), os reis, que foram sucessores de João Sem Terra, tinham certa dificuldade em acatar as decisões do Conselho dos Comuns sobre os assuntos de arrecadação; havia uma grande divergência, pois o povo e o Parlamento não concordavam com as ações do Rei.

Foi somente a partir de 1789 que a Constituição Francesa consagrou um princípio o qual afirmava que: "Os Impostos só poderiam ser cobrados com a anuência do povo". Mais tarde, em 1817, a Assembleia Nacional impôs um controle sobre as finanças Públicas, onde ficou decidido que as despesas de um Ministério não poderiam ultrapassar o total da dotação destinada (SILVA, 2011).

Houve no Brasil muitas discordâncias acerca das Finanças Públicas, mas somente a partir de 1808, com a chegada de D. João VI, foi criado o Erário Régio (tesouro) e estabelecido que seria gerido pelo Conselho da Fazenda com as funções de contabilizar, distribuir e realizar os procedimentos para o controle do Patrimônio (GIACOMONI, 2010).

Maia (2010) diz que em várias Constituições ao decorrer dos anos, discutiu-se sobre orçamento, mas foi na Constituição Federal de 1988 que o Orçamento ganhou uma grande importância por ser o mecanismo mais complexo para a alocação de recursos. Foram criados novos conceitos, normas e confirmados princípios já existentes.

\section{Orçamento Público}

O orçamento público é um mecanismo aprovado por lei, que contribui diretamente no andamento dos serviços na Administração Pública, no qual, metas, objetivos e diretrizes são traçadas, especificadas prioridades e demandas dos habitantes em um determinado tempo, visando que a execução das atividades aconteça de forma eficaz e transparente. (GIACOMONI,2010). 
atendimento das necessidades econômicas e sociais da população, bem como da aplicação desses recursos por parte do Estado (FORTES, 2011, p.76).

A iniciativa da elaboração do orçamento é de responsabilidade do Poder Executivo em todos os âmbitos do governo, (Municípios, Estados, Distrito Federal e União), eleitos pelo voto popular para representar a sociedade, na busca de soluções dos problemas e angustias da população.

De acordo com Àvila (2012), para que a Administração Pública possa executar suas tarefas de forma eficiente, é necessário utilizar mecanismos que legalizem e legitimem suas atividades, e esse mecanismo é o Orçamento Público.

Já Silva (2011), relata que o Orçamento é como um ato de prevenção que autoriza as despesas e receitas que o Governo deve realizar em um exercício.

Tendo em vista que essas ações são executadas para obter resultados que visam o bem comum dos cidadãos, é necessário de uma maior participação direta dos mesmos nessas decisões, de modo que possam expressar as pautas que trazem preocupações para seu município e dar sugestões para, junto com o Executivo e Legislativo, elaborarem o Orçamento.

Na visão de Silva (2016), no Orçamento deve conter variados propósitos ligados a busca de resultados e controle. Ele ressalta ainda que o Orçamento não é somente a previsão de algo que irá acontecer, mas que determina as metas de forma que todos se empenhem para alcançar bons resultados nas execuções dos trabalhos.

Com base no que foi visto, nota-se que o Orçamento é um mecanismo de total relevância para a Administração Pública, pois é através dele que são constituídas ações de planejamento, para qualificar os serviços que são ofertados ao povo.

\section{Orçamento e Planejamento}

Conforme Faria (2015, p.2)," O planejamento é uma das mais importantes ferramentas de administração. $\mathrm{O}$ conceito de planejar está intimamente ligado à necessidade de se ter conhecimento prévio das atitudes a serem tomadas e das ações a serem desempenhadas.”.

Antes de programar a execução de qualquer atividade é necessário um planejamento preciso e eficaz, é nessa etapa que são decididas quais serão as prioridades a serem desenvolvidas no decorrer do trabalho. 
Na visão de Silva (2011, p.179)," O planejamento deve ser anterior à realização das ações de governo, sendo entendido como um processo racional para definir objetivos e determinar os meios para alcança-los.”

Ávila (2012) discorre sobre a tese de que o Orçamento é um mecanismo do Planejamento, ou seja, é uma sondagem de forma geral do que foi estabelecido para se chegar a um determinado objetivo.

A Constituição Federal de 1988 em seu art. 165, estabeleceu como dispositivo de planejamento Governamental os seguintes planos: Plano Plurianual (PPA); Lei das Diretrizes Orçamentárias (LDO) e Lei Orçamentária Anual (LOA) que são elaborados em todos os âmbitos do Governo.

Silva (2011) relata a importância da elaboração e do debate sobre os mecanismos de Planejamento de forma que os mesmos sejam capazes de mostrar com clareza a responsabilidade Governamental para com o povo, e que o Orçamento deve apontar os propósitos almejados pela coletividade, da qual é representada pelo Governo.

Os mecanismos de Planejamento são de grande importância para a elaboração do Orçamento, visto que é através dos mesmo que o referido ganha mais confiabilidade e veracidade, tendo em vista que as atividades que são desenvolvidas de forma bem planejada, tem maiores possibilidades de evitar erros e alcançar bons resultados.

\section{Plano Plurianual - PPA}

De acordo com Kohama (2014), o PPA é uma estratégia de médio prazo, que busca determinar e organizar as ações do Governo, resultando no alcance dos objetivos e metas estabelecidos em um determinado tempo e executadas por todas as esferas do poder Público.

Conforme está presente na Constituição Federal de 1988 em seu Art. $165 \S 1^{\text {o. }}$.

$\S 1^{\circ}$. A lei que instituir o plano plurianual estabelecerá, de forma regionalizada, as diretrizes, objetivos e metas da administração pública federal para as despesas de capital e outras delas decorrentes e para as relativas aos programas de duração continuada.

(...) (BRASIL, 1988).
}

Já para Angélico (2014) O Plano Plurianual é um Planejamento Geral das atividades para um tempo determinado. Esse projeto serve de suporte para a elaboração dos demais 
mecanismos planejáveis do Orçamento: a Lei das Diretrizes Orçamentárias (LDO) e a Lei Orçamentária Anual (LOA)

Ávila (2012) destaca que o PPA é um mecanismo de Planejamento indispensável, logo nele está presente todas as ações a serem executadas pelo Gestor em todo seu mandado, e é através do mesmo que são elaboradas as demais leis do Orçamento. O autor também ressalta que o Gestor, no seu primeiro ano de Governante, irá executar o PPA construído pelo seu antecessor.

Está presente no Art. 166 da Constituição Federal de 1988, que o Plano Plurianual e as demais leis do Orçamento serão estudados, avaliados e fiscalizados pelas duas casas do Congresso Nacional.

Conforme o art. 165 da $\mathrm{CF} / 88, \S 9^{\circ}$

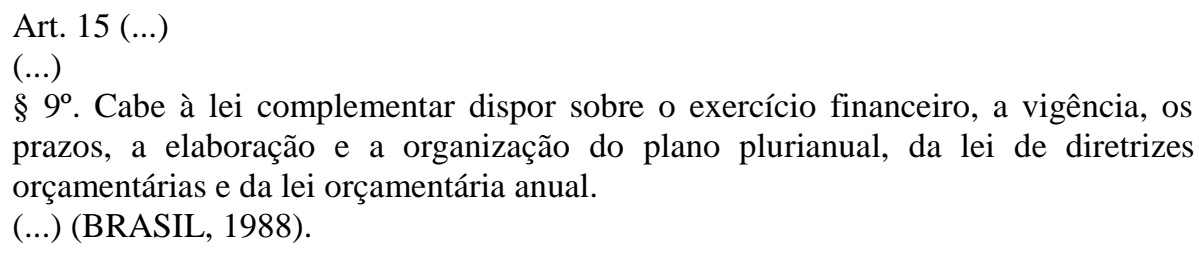

A Constituição Federal de 1988 no seu Art. $165 \S 9^{\circ}$, diz que os prazos devem ser estabelecidos através de Lei Complementar, quando não existe a referente Lei é definido mediante o Ato das Disposições Constitucionais Transitórias ADCT precisamente no art. $35, \S$ $2^{\circ}$, no qual relata que o Plano Plurianual (PPA) estará em vigor até o final do exercício financeiro, e na esfera federal deve ser encaminhado quatro meses antes do término do ano civil, ou seja, até 31 de agosto, e devolvido para ser sancionado até o fim dos trabalhos do Legislativo, dia 15 de dezembro.

O PPA abrange quatro exercícios financeiros. O gestor subsequente, sempre executará um ano de plano elaborado pelo governante anterior, pelo fato dos serviços não poderem ser interrompidos. Nessa lei não são exemplificados valores, porém deve existir um grande cuidado na elaboração, pois são traçadas estratégias de Governo a médio prazo que devem ser cumpridas corretamente (ÁVILA, 2012)

\section{Leis das Diretrizes Orçamentárias - LDO}

Nas palavras de Kohama (2014) a Lei das Diretrizes Orçamentárias é nada mais do que a responsável por conduzir e da um norte na construção da Lei Orçamentaria anual (LOA).

Conforme a Constituição Federal de 1988, no Art. $165 \S 2^{\circ}$ : 
Art. $165(\ldots)$

(...)

$\S 2^{\circ}$ A lei de diretrizes orçamentárias compreenderá as metas e prioridades da administração pública federal, incluindo as despesas de capital para o exercício financeiro subsequente, orientará a elaboração da lei orçamentária anual, disporá sobre as alterações na legislação tributária e estabelecerá a política de aplicação das agências financeiras oficiais de fomento.

(...) ( BRASIL, 1988).

Ávila (2012) diz que a LDO é um instrumento do Planejamento Orçamentário que não se preocupa com valores, mas empenha-se com a parte da organização de metas e objetivos, diferenciando-se do PPA apenas no prazo de elaboração que é apenas de um ano Civil.

Com base na edição da Lei de Responsabilidade Fiscal no ano de 2000, foi enaltecida a relevância da Lei das Diretrizes Orçamentárias (LDO) e foram implementadas as seguintes competências para execução do Orçamento, presente no Art. $4^{\circ}$ :

Art, $4^{\circ}$. Equilíbrio entre receitas e despesas; Critérios e forma de limitação de
empenho, a ser efetivada nas hipóteses previstas na alínea $b$ do inciso II deste artigo,
no art. 9o e no inciso II do $\$ 11^{\circ}$ do art. 31 ; Normas relativas ao controle de custos e à
avaliação dos resultados dos programas financiados com recursos dos orçamentos;
Demais condições e exigências para transferências de recursos a entidades públicas e
privadas; metas fiscais, que constarão de anexo próprio, denominado Anexo de Metas
Fiscais, acompanhado de demonstrativo; riscos fiscais, que constarão de anexo
próprio, denominado Anexo de Riscos Fiscais ( BRASIL, 2000).

Essa implementação tornou a Lei das Diretrizes Orçamentária mais complexa pelo fato de incluir e quantificar a arrecadação e os gastos ocorridos em um determinado ano. É importante lembrar também que para cada Plano Plurianual serão elaboradas quatro LDO’s que deverão, ao final de quatro anos, concluir a execução de todas as metas e objetivos estipulados na PPA (ÁVILA, 2012).

Segundo a ADCT art. 35, § 20. “o projeto de lei de diretrizes orçamentárias será encaminhado até oito meses e meio antes do encerramento do exercício financeiro e devolvido para sanção até o encerramento do primeiro período da sessão Legislativa."

A Lei das Diretrizes Orçamentárias é imprescindível para a elaboração e execução do Orçamento, visto que nesse plano são contidas as metas, demandas e prioridades da população para um exercício financeiro. 


\section{Lei Orçamentária Anual - LOA}

Conforme o Guia Contábil da Lei de Responsabilidade Fiscal (2003, p. 83), “a LOA é o instrumento de planejamento utilizado pelos governantes para gerenciar as receitas e despesas públicas em cada exercício financeiro".

Já para Kohama (2014), a Lei Orçamentária Anual é a efetivação dos planos traçados no PPA, obedecendo a Lei das Diretrizes Orçamentárias, construindo ações e buscando alcançar os objetivos.

De acordo com a Constituição Federal de 1988, em seu artigo 165 e incisos, a LOA compreende:

\footnotetext{
Art. 165(...)

I - o orçamento fiscal referente aos Poderes da União, seus fundos, órgãos e entidades da administração direta e indireta, inclusive fundações instituídas e mantidas pelo Poder Público;

II - o orçamento de investimento das empresas em que a União, direta ou indiretamente, detenha a maioria do capital social com direito a voto;

III - o orçamento da seguridade social, abrangendo todas as entidades e órgãos a ela vinculados, da administração direta ou indireta, bem como os fundos e fundações instituídos e mantidos pelo Poder Público (BRASIL, 1988).
}

É na LOA que são previstas receitas e fixadas as despesas de um exercício financeiro. Ele é elaborada pelo Executivo e enviada ao Legislativo para a aprovação. Sua elaboração deve ser de acordo com o que foi planejado na PPA e direcionado na LDO.

Em relação aos prazos da Lei Orçamentária Anual, consta no Ato das Disposições Constitucionais Transitórias (ADCT) no art. $35, \S 2^{\circ}$ diz que: “o projeto de lei orçamentária da União será encaminhado até quatro meses antes do encerramento do exercício financeiro e devolvido para sanção até o encerramento da sessão legislativa."

No âmbito Federal, a LOA deverá ser destinada pelo Executivo até o dia 31 de agosto do exercício financeiro anterior, e devolvido para sanção até 15 de Dezembro.

Os mecanismos de Planejamento estão diretamente interligados é notório que para cada Plano Plurianual são elaboradas quatro leis das Diretrizes Orçamentária e a mesma quantidade de Leis Orçamentárias Anuais. É importante salientar que a LOA não será aprovada, caso não contenha o que foi planejado no PPA e direcionado na LDO (ÁVILA, 2012) 


\section{Tipos de Orçamento}

Na busca por melhorar o Planejamento na Gestão Pública e a alocação dos bens públicos, vários tipos de Orçamentos foram utilizados durante a evolução da sociedade (ÁVILA, 2012).

\section{Orçamento Tradicional}

O Orçamento tradicional, segundo Angélico (2014), era um simples confronto do que o Governo arrecadava e do que seria gasto, não havia uma preocupação com o planejamento das atividades e não eram analisadas as prioridades naquele momento. Só existia melhoria nos Serviços se as Receitas ultrapassassem as Despesas.

Fortes (2011, p.77) diz que "Um dos seus objetivos principais era o de possibilitar aos órgãos do Legislativo um controle político sobre os gastos públicos, mantendo o equilíbrio financeiro entre as receitas e despesas, evitando, assim, a expansão da despesa pública"

Segundo Ávila (2012), atualmente, o Orçamento Tradicional não é utilizado nas Gestões pelo fato de não conter um cunho de Planejamento.

\section{Orçamento Base Zero}

Este tipo de Orçamento cobra um grande conhecimento do Gestor nas demandas e prioridades da população, e exige que todos os seus projetos sejam justificados. Ao contrário do orçamento tradicional, o orçamento base zero desliga-se da preocupação com a verificação das despesas e receitas e pensa mais no Planejamento e controle na execução das tarefas.

Para Kohama (2014, p.63), "O processo de Orçamento base zero baseia-se na "preparação de pacotes de decisão" e, consequentemente, na escolha do nível de objetivo através da definição de prioridades, confrontando-se incrementos pela ponderação de custos e benefícios". O autor expressa o fato de que o Orçamento base zero possui várias funções, tais como: analisar custos e benefícios, consequências de não execução das ações, avaliação de desempenho, livrar-se de duplicidade e entre outros. 


\section{Orçamento por Programas}

Para Fortes (2011, p.79), "O orçamento-programa é portanto, um plano de trabalho no qual são detalhados os programas e despesas que se pretende realizar durante o exercício financeiro, evidenciando a política econômica do Governo." Ou seja, ele demonstrados as demandas e prioridades em um determinado tempo, os valores, e os custos que são necessários para executar as atividades.

O Orçamento por programas é o tipo mais utilizado e o que se encaixa com as necessidades atualmente, visto que é o que tem uma preocupação maior em planejar as atividades tendo em vista serviços de curto e longo prazo (ÁVILA, 2012).

Angélico (2014) relata que o Orçamento Programa se preocupa em executar as prioridades e metas para o Governo ao decorrer do seu mandato, nele são exemplificados as receitas previstas para serem arrecadadas e as despesas que serão executadas de forma bem programada.

Já Silva (2011), diz que a elaboração do Orçamento Programa é um trabalho bem preparado que visa a alocação correta dos recursos Públicos, para que assim possam ser ofertados Serviços Públicos de boa qualidade para a população.

\section{Composição do Orçamento}

O orçamento é de total relevância para a Administração Pública, pois ele é um instrumento que auxilia de forma eficaz no planejamento e execução das atividades do setor Público, e na LOA são previstas as receitas e fixadas as despesas de um ano civil.

A Lei 4.320/1964 precisamente no seu art.35, incisos I e II diz que pertence ao exercício financeiro às receitas nele arrecadadas e as despesas nele legalmente empenhadas.

\section{Receitas Públicas}

Receitas Públicas são recursos previstos em legislação e arrecadados pelo Poder Público no intuito de realizar investimentos na saúde, educação, segurança, saneamento e entre outras áreas que são demandas e necessidades do povo.

Kohama (2015, p. 66), conceitua Receita Pública como: 
Entende-se, genericamente, por Receita Pública todo e qualquer recolhimento feito aos cofres públicos, quer seja efetivado através de numerário ou outros bens representativos de valores - que o Governo tem o direito de arrecadar em virtude de leis, contratos ou quaisquer outros títulos de que derivem direitos a favor do Estado, quer seja oriundo de alguma finalidade específica, cuja arrecadação lhe pertença ou caso figure como depositário dos valores que não lhe pertencerem.

As Receitas são classificadas inicialmente em dois grupos: Receitas Orçamentárias e Receita Extra Orçamentária.

Segundo Angélico (2014), Receita Orçamentária é aquela que está prevista em lei e está presente no Orçamento Público, já a Receita Extra Orçamentária é aquela que não está presente no Orçamento, é mantida em contas que estão presentes no plano de conta organização.

Ávila (2012) diz que as Receitas Orçamentárias são aquelas que dependem de autorização do Legislativo para serem fixadas e executadas, já as Extra Orçamentárias representam os recursos que adentram os cofres Públicos de forma temporária e não modificam o Patrimônio.

Também são classificadas sobre o enfoque econômico de acordo com o artigo 11 da Lei 4.320/1964, em Receitas Correntes e Receitas de Capital:

Art. $11(\ldots)$

$\S 1^{\circ}$ - São Receitas Correntes as receitas tributária, de contribuições, patrimonial, agropecuária, industrial, de serviços e outras e, ainda, as provenientes de recursos financeiros recebidos de outras pessoas de direito público ou privado, quando destinadas a atender despesas classificáveis em Despesas Correntes

(...) (BRASIL, 1964).

Na visão de Kohama (2014), as Receitas Correntes são ingressos financeiros que são oriundas as atividades do estado e está diretamente vinculado a uma despesa corrente.

Art. 11 (...)

$\S 2^{\circ}$ - São Receitas de Capital as provenientes da realização de recursos financeiros oriundos de constituição de dívidas; da conversão, em espécie, de bens e direitos; os recursos recebidos de outras pessoas de direito público ou privado, destinados a atender despesas classificáveis em Despesas de Capital e, ainda, o superávit do Orçamento Corrente.

(...) (BRASIL, 1964).

As Receitas de Capital são Recursos Financeiros, provenientes de atividades não operacionais é aplicada em despesas não operacionais, visando cumprir as metas traçadas nos programas e ações do Governo (SILVA, 2011). 


\title{
Despesas Públicas
}

Kohama (2014, p. 98) define Despesa Pública como sendo:

\begin{abstract}
Os gastos fixados na lei orçamentária ou em leis especiais e destinados à execução dos serviços públicos e dos aumentos patrimoniais; à satisfação dos compromissos da dívida pública; ou ainda à restituição ou pagamento de importâncias recebidas a título de cauções, depósitos, consignações etc.
\end{abstract}

Para Angélico (2014, p.62), "Despesa Pública é todo pagamento efetuado a qualquer título pelos Agentes pagadores." Ou seja, é todo Gasto realizado pelo Governo, para a realização de Serviços Públicos.

Já na perspectiva de Silva (2011), a despesa é todo custo que o Estado tem para a execução das Atividades Públicas nos termos das Leis ou de outros dispositivos, visando a satisfação da Coletividade.

Ávila (2012) diz que as despesas fazem parte do Orçamento diretamente e que mostram todos os elementos necessários para que a Gestão Pública tenha eficácia nos seus Serviços, utilizando as despesas para o custeamento.

Assim como as Receitas, as Despesas também são classificadas inicialmente em dois grupos: Despesas Orçamentárias e Despesas Extra Orçamentárias.

Para Kohama (2014), as Despesas Orçamentárias são aquelas que não podem ser realizadas sem um crédito equivalente, dependem do Poder Legislativo e que estão precisamente no Orçamento para serem realizadas. Já as Despesas Extra Orçamentárias são aquelas que não constam informações no Orçamento Público e não dependem de autorização do Poder Legislativo, pois elas correspondem a entradas de Receitas Extra Orçamentárias, como consignações, calções e etc.

O art. 12 da Lei 4.320/1964 Classifica as Despesas Públicas conforme o enfoque Econômico em: Despesas Correntes e Despesas de Capital

Despesa Corrente é todo gasto de cunho Operacional realizado pela a Administração Pública para a preservação e andamento de seus órgãos e que não participam na construção ou obtenção de um bem capital (KOHAMA, 2014). Estão entre as Despesas Correntes segundo a Lei 4.320/64 as Despesas de Custeio e as Transferências Correntes.

Despesa de Capital segundo Ávila (2012), são aquelas cujo o objetivo é quitar as contas da Administração Pública, constituindo ou comprando bens de Capital que já estão em uso pelo Órgão Público. As Despesas de Capital estão classificadas segundo a Lei 4.320/64 em Investimentos, Inversões Financeiras e Transferências de Capital. 


\section{Princípios Orçamentários}

O Orçamento Público é um importante instrumento de auxílio da Administração Pública para a execução das atividades. Como o mesmo exerce essa função de tamanha responsabilidade, é necessário que haja algum dispositivo para dar suporte a sua elaboração e trazer mais autenticidade e veracidade as informações contidas nele. Os princípios Orçamentários servem para isso, dar um norte e servir de base para a criação do Orçamento.

Por ser um instrumento Legislativo e autorizativo que regula a ação do poder Público, deve conter no Orçamento todas as receitas e despesas, para que as atividades de controle do Legislativo sejam eficazes; os princípios servem de garantia para a construção do Orçamento de forma correta (SILVA, 2011).

Conforme a Lei 4.320/64, em seu art. $2^{\circ}$ " A Lei do Orçamento conterá a discriminação da receita e despesa de forma a evidenciar a política econômica financeira e o programa de trabalho do Governo, obedecidos os princípios de unidade, universalidade e anualidade". O Princípio da Unidade diz que o Orçamento deve ser uno, ou seja, só deve existir somente um Orçamento para cada Exercício Financeiro e para cada Órgão do Poder Público. Já o Princípio da Universalidade ressalta que todas as despesas e as despesas devem ser inclusas no Orçamento. Quem fica de fora está impedido de receber recursos oriundos do Orçamento. O Princípio da Anualidade estabelece que as previsões das receitas e despesas do Orçamento devem ser utilizadas pelo período de tempo estipulado em um ano civil (ÁVILA, 2012).

O Princípio da Exclusividade segundo a CF de 1988 no seu Art.165 § 8ª , diz que só deve constar no Orçamento matérias orçamentárias e não cuidar de assuntos estranhos a previsão de receitas e fixação de despesas

O Princípio da Legalidade está presente na Constituição Federal de 1988 precisamente no art.37 e diz que só é permitido fazer somente o que está previsto em Lei.

No Princípio da Publicidade segundo a Lei Complementar $n^{\circ}$ 101, de 4 de maio de 2000, o Orçamento deve ser divulgado através dos veículos de comunicação, em meios eletrônicos e até em audiência pública para o para conhecimento de todos. O princípio também está presente no art.37 da $\mathrm{CF} / 88$.

Segundo o inciso IV, do art.167, da Constituição de 1988, no Princípio da Não Afetação da Receita é vedada a vinculação de receita de imposto a órgão, fundo ou receita.

No Princípio do Orçamento Bruto conforme consta no art. $6^{\circ}$, da Lei 4.320/64, as receitas e as despesas devem constar na Lei Orçamentária e de Créditos Adicionais pelos seus valores brutos, sem nenhuma dedução 
No Princípio do Equilíbrio Orçamento deve manter uma igualdade entre as receitas previstas e as despesas fixadas. O art. 167, inciso III, veda: "a realização de operações de créditos que excedam o montante das despesas de capital".

O Princípio da Especificação segundo a Lei 4.320/64 veda qualquer dotação global do Orçamento. Deve ser especificado com o que vai ser gasto.

\section{Ciclo Orçamentário}

Para Paludo (2013, p.105), “O ciclo orçamentário compreende o período de tempo em que se processam as atividades típicas do Orçamento Público; ou seja, a elaboração orçamentária, a aprovação, a execução orçamentária e financeira, e o controle e avaliação.”

O Ciclo Orçamentário é o período pelo qual são processadas as atividades contidas no Orçamento. É importante salientar e não confundir o Ciclo Orçamentário com o Exercício Financeiro, pois o mesmo é uma das etapas do Ciclo.

É na fase de Elaboração, segundo Ávila (2012), que o Planejamento é colocado em prática, são programadas e estabelecidas às ações, metas e diretrizes a serem alcançadas, especificados os valores de receitas previstas e despesas fixadas e depois a entrega da proposta do Executivo ao Legislativo.

De acordo com Kohama (2014), a fase de Estudo e Aprovação é de responsabilidade do Legislativo. Essa etapa é muito importante pelo fato de ser necessária a realização de uma grande análise por parte dos representantes do povo. Deve observar se o Orçamento foi elaborado de maneira correta, de acordo com as necessidades da População. O Poder Legislativo é obrigado a devolver o Projeto ao Executivo para ser sancionado antes do fim dos trabalhos da casa Legislativa.

A execução do Orçamento de acordo com Ávila (2012, p.107), consiste no "Período no qual a proposta, já convertida em lei, deverá ser posta em prática com a finalidade de concretizar todos os objetivos estabelecidos." Ou seja, é a fase na qual o Orçamento é colocado em prática, buscando desenvolver as atividades de forma transparente e satisfatória para a população.

Avaliação e Controle são a última etapa do Ciclo Orçamentário, e segundo a Constituição Federal de 1988, é dividido entre Controle Interno e Externo. O controle Externo será efetivado com a ajuda do Tribunal de contas com a finalidade de apreciar, fiscalizar e julgar as contas do Governo. O controle Interno é exercido segundo a Constituição pela própria Administração em cada âmbito do Governo por meio de seus órgãos. 
Para Paludo (2013, p. 106), "Há diferença entre controle e avaliação: o controle consiste na verificação da conformidade, propõe ações corretivas e tem foco retrospectivo. A avaliação visa ao aperfeiçoamento da gestão, avalia resultados e tem foco prospectivo".

É importante destacar a importância do Ciclo orçamentário para a execução dos Serviços Públicos em todas suas etapas, ele é um grande responsável por levar transparência as atividades da Administração Pública.

\section{Metodologia}

O presente trabalho consiste em uma pesquisa descritiva, exploratória e bibliográfica, na qual envolve estudos acerca de conceitos e divisões sobre a Gestão Pública, referentes aos processos que passam Orçamento Público, no qual vai desde a elaboração, a sua execução. No artigo foram expostas as características e os objetivos acerca do assunto estudado. Para Gil (2008) as pesquisas descritivas são aquelas que tem como propósito a apresentação das particularidades de determinado assunto ou população. Já a exploratória consiste em mostrar esclarecimentos e converter conceitos sobre determinadas ideias, pretendendo a elaboração de problemas mais claros ou hipóteses de pesquisas para estudos futuros.

Inicialmente foi realizado o levantamento bibliográfico, no qual foram utilizados livros, artigos, dissertações, teses sobre o assunto, além de consultas em sites de instituições que contém estudos sobre o tema abordado. A pesquisa bibliográfica segundo Vergara (2005) constitui-se de um estado sistematizado desenvolvido com base em material publicado em revista, livros, jornais e consulta em sites da internet, isto é material acessível ao público geral.

A pesquisa constitui-se de um estudo de revisão teórica, focando no tema do orçamento público e tendo como base, dentre outros autores citados ao longo do estudo, a literatura apresentada por Kohama (2014) e Ávila (2012) que, por meio de seus estudos sobre orçamento Público, consideram esse instrumento de planejamento um exemplo de experiência e auxílio para a Administração Pública, uma vez que atende aos requisitos desse modelo teórico.

\section{Considerações Finais}

O trabalho expressa de forma clara e objetiva as definições acerca do Orçamento Público e da sua importância para a Gestão. Destacando desde a origem no ano de 1215, a evolução ao longo dos anos, e a estrutura que é utilizada nos dias atuais. 
De início foi apresentado na presente pesquisa a relação do Orçamento com a Administração Pública, visto que o mesmo é considerado um relevante dispositivo de apoio para o desenvolvimento e execução das atividades do Setor Público, responsável por levar eficácia e transparência aos serviços. Discorreu-se também sobre a Origem do Orçamento na Inglaterra quando foi Outorgada a Carta Magna que foi considerada o pilar para o Surgimento do Orçamento.

Em seguida foram abordados os conceitos básicos sobre o Orçamento que é considerado um mecanismo de programação para aplicação de recursos esperados futuramente. A relação entre Orçamento e Planejamento que é uma temática significativa, pelo fato de que é necessário planejar qualquer atividade antes da sua execução, no qual se concretizou com a criação dos Instrumentos de Planejamento no qual estão presentes na Constituição Federal de 1988 e são: Plano Plurianual (PPA) que estabelece as metas, prioridades e diretrizes do Governo para um período de quatro anos, a Lei das Diretrizes Orçamentárias (LDO) que funciona como um elo entre a PPA e a LOA, e tem a função de nortear a elaboração da Lei Orçamentária, e por fim a Lei Orçamentária Anual que é responsável pela execução do que foi planeado na PPA e direcionado na LDO, é na LOA que estará presente os projetos que serão executados no período de um exercício financeiro.

Logo após foi falado sobre as tipificações do Orçamento e demonstrado qual o tipo que está apto para desenvolver as atividades de Planejamento atualmente. Também explanou-se a respeito das Receitas e Despesas e suas classificações, é notório que essa temática tem uma importância significativa dentro desse dispositivo, pois é necessário saber qual a Receita prevista e Despesa fixada, para de fato poder planejar a melhor estratégia para a execução dos serviços e buscar a satisfação da coletividade.

Em seguida foi relatado todos os princípios que regem a elaboração do Orçamento, no qual devem ser obedecidos rigidamente para que o referido passe mais fidedignidade e transparência para a população. Por fim foi falado sobre o Ciclo Orçamentário, que é o período no qual são processadas as atividades Orçamentárias, que vai desde a elaboração, até o controle.

O Orçamento Público é um dos grandes responsáveis pelo o Andamento dos Serviços Públicos, é notória a importância que ele possui dentro da Administração Pública, visto que o mesmo auxilia os gestores nas tomadas de decisões, da mesma forma que legaliza e legitima as atividades do setor público. É preciso lembrar que o Planejamento é fundamental para a elaboração de um Orçamento claro e objetivo, no qual trará bons resultados para a Gestão e mais transparência aos processos. 


\section{Referências}

ANGÉLICO, João. Contabilidade Pública. $8^{\circ}$ ed. São Paulo: Atlas, 2014.

ÁVILA, Carlos Alberto. Orçamento Público. 2012. Disponível em: http://ead.ifap.edu.br/ netsys/public/livros/Livros\%20Curso\%20Servi\%C3\%A7os\%20P\%C3\%BAblicos/M\%C3\%B 3dulo\%20II/Or\%C3\%A7amento\%20P\%C3\%BAblicos/Livro\%20Orcamento\%20Publico.pdf. Acesso em: 20 Set. 2018.

BACHTOLD, Ciro. Noções de Administração Pública. 2012. Disponível em: http://ead.ifap. edu.br/netsys/public/livros/Livros\%20Curso\%20Servi\%C3\%A7os\%20P\%C3\%BAblicos/M\% C3\%B3dulo\%20I/Capa\%20Nocoes\%20Administracao\%20Publica_IFAP/Livro\%20Nocoes\% 20Administracao\%20Publica.pdf. Acesso em: 22 Set. 2018.

BRASIL. Constituição Federal (1988). Constituição Federal da República Federativa do Brasil, de 15 de outubro de 1988. Disponível em http://presidência.gov.br/legislação Acesso em 15 Ago. 2018.

. Lei 4.320, de 17 de março de 1964. Estatui Normas Gerais de Direito Financeiro para elaboração e controle dos orçamentos e balanços da União, dos Estados, dos Municípios e do Distrito Federal. Diário Oficial [da] República Federativa do Brasil, Brasília, DF, 17 mar. 1964. Disponível em: <http://www.planalto.gov.br/ccivil_03/leis/14320.htm>. Acesso em: 22 Set. 2018 .

Lei complementar n. 101, de 4 de maio de 2000. Estabelece

normas de finanças públicas voltadas para a responsabilidade na gestão fiscal e dá outras providências. Diário Oficial [da] República Federativa do Brasil, Brasília, DF, 04 mai. 2000. Disponível em: <http://www.planalto.gov.br/ccivil_03/leis/lcp/lcp101.htm>. Acesso em: 21 Set. 2018.

FARIA, Karoliny. O Planejamento Orçamentário na Administração Pública. 2010. Disponível em: https://karolcfaria.jusbrasil.com.br/artigos/242116319/o-planejamento-orcamentario-naadministracao-publica. Acesso em 22 Set. 2018.

FORTES, João. Contabilidade Pública. 10º ed. Brasília: Franco e Fortes, 2011.

GIACOMONI, James. Orçamento Público. 15ª ed. São Paulo: Editora Atlas, 2010.

GIL, Antonio Carlos. Métodos e técnicas de Pesquisa Social. $6^{\circ}$ ed. São Paulo: Atlas, 2008.

KOHAMA, Hélio. Contabilidade Pública Teoria e Prática. 14 ed. São Paulo: Atlas, 2014.

MAIA, Wagner. História do Orçamento Público no Brasil. São Paulo : 2010. Disponível em http://agesp.org.br/wp-content/uploads/2013/05/Artigo HistOrcamento.pdf. Acesso em 20 Set. 2018.

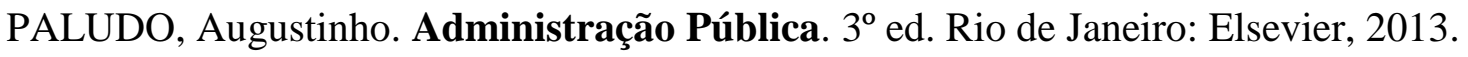


SILVA, Lino Martins. Contabilidade Governamental. $9^{\circ}$ ed. São Paulo: Atlas, 2011.

SILVA, Lucas Vinicius Oliveira. Planejamento Orçamentário. 2016. Disponível em http://www.administradores.com.br/artigos/academico/planejamento-orcamentario/95024/. Acesso em: 21/09/2018.

VEIGA, CLÓVIS DE ANDRADE. Direito financeiro e aplicado (planejamento, elaboração, execução e controle orçamentário). São Paulo: Ed. Revista dos Tribunais, 1975.

VIANA, ARÍZIO. Orçamento brasileiro. 2a ed. Rio de Janeiro: Ed. Financeiras, 1950.

VERGARA, SC.; Projetos e Relatórios de Pesquisa em Administração. São Paulo. Atlas. 2005.

Como citar este artigo (Formato ABNT):

ALMEIDA, Hellen Martins de; COSTA, Antonia Vadelucia. Orçamento Público como Mecanismo de Planejamento para a Gestão. Id on Line Rev.Mult. Psic., 2019, vol.13, n.43, p. 559-577. ISSN: 19811179.

Recebido: 22/11/2018;

Aceito: 23/11/2018 